Секция 9. Углеродные и графеноподобные наноматериалы, дихалькогениды переходных металлов, перовскиты, органические полупроводники, молекулярные системы

\title{
Рекомбинация носителей заряда в аморфных органических полупроводниках: эффекты пространственной корреляции энергетического ландшафта
}

Новиков С.B. ${ }^{1,2}$, Тамеев А.P. ${ }^{1,2}$

${ }^{1}$ Институт физической химии и электрохимии им. А.Н. Фрумкина РАН, 119071, Москва, Ленинский просп. 31

${ }^{2}$ Национальный исследовательский университет «Высшая школа экономики», 101000, Москва, Мясниикая ул. 20

DOI 10.34077/Semicond2019-385

Характерной чертой аморфных органических полупроводников является сильная пространственная корреляция случайного энергетического ландшафта $U(\vec{r})$, оказывающая существенное влияние на прыжковый транспорт носителей заряда в этих материалах, в том числе и на процесс рекомбинации носителей. Между тем рекомбинация носителей заряда в коррелированном случайном ландшафте практически не исследовалась. В докладе представлена теория такой рекомбинации [1], наиболее подробно рассмотрен случай полярного аморфного материала (дипольного стекла), в котором энергия носителя определяется взаимодействием со случайно расположенными и ориентированными диполями и соответствующая корреляционная функция убывает очень медленно $C(\vec{r})=\langle U(\vec{r}) U(0)\rangle \propto 1 / r$. Рекомбинация может быть описана как происходящая между частицами, эффективный заряд которых зависит от глубины ямы, в которой они захвачены. Величина заряда уменьшается с ростом глубины ямы, ослабляя притяжение между электроном и дыркой. Последующее усреднение по плотности занятых состояний дает

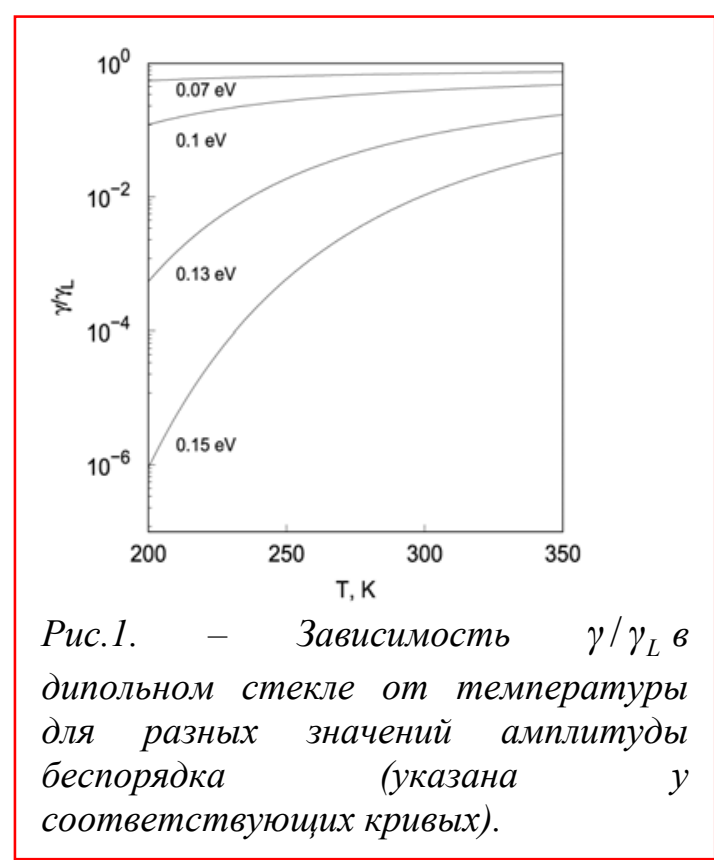
возможность вычислить полную константу скорости рекомбинации $\gamma$. Аналогичное вычисление возможно и для других типов корреляционной функции, например описывающей неполярный материал с доминирующим вкладом молекулярных квадруполей, хотя качественная картина рекомбинации эффективных зарядов будет неприменима.

Основной результат заключается в том, что коррелированный электростатический беспорядок неизбежно ведет к уменьшению $\gamma$ по сравнению с ланжевеновским значением $\gamma_{L}=4 \pi e\left(\mu_{p}+\mu_{n}\right) / \varepsilon$ (Рис. 1), и чем сильнее пространственные корреляции, тем меньше значение $\gamma$ (здесь $\mu_{p}$ и $\mu_{n}$ подвижности дырок и электронов, $\varepsilon$ - диэлектрическая постоянная среды). Это именно эффект корреляций, поскольку сам по себе энергетический беспорядок, вне зависимости от его амплитуды, не ведет к отличию $\gamma$ от $\gamma_{L}$. Этот вывод хорошо согласуется с результатами компьютерного моделирования рекомбинации в средах без корреляции [2].

Работа выполнена при финансовой поддержке проекта РФФИ 16-29-06423_офи-м и Программы фундаментальных исследований НИУ ВШЭ.

[1] S.V. Novikov, J. Phys. Chem. C, 122, 22856 (2018).

[2] C. Groves, N.C. Greenham, Phys. Rev. B, 78, 155205 (2008). 